\title{
Poorly managed childhood pain can have lifelong consequences
}

\author{
— Cite as: CMAJ 2019 July 8;191:E771-2. doi: 10.1503/cmaj.109-5768
}

Posted on cmajnews.com on June 18, 2019.

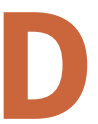

oes it matter if an infant feels the pinch of an injection? Or if a preemie feels the abrasion of a feeding tube? Not so long ago, it was widely believed that the very young couldn't even feel pain. But a new campaign is warning that unmanaged pain in early childhood not only hurts, it can have long-lasting undesirable effects and needs to be tackled more effectively.

"There's this belief that pain will toughen you up and you'll get used to it," says Christine Chambers, Canada Research Chair in Children's Pain at Dalhousie University. "But the reverse happens. There's a lot of science showing sensitization, and that poorly managed pain early in life actually causes you to feel more pain later."

Chambers is spearheading a campaign, Solutions for Kids in Pain, dubbed SKIP, which launched in April. It aims to bring together families, clinicians, researchers and health system managers to help ensure children's pain is managed appropriately.

"There is a pretty substantive literature looking at the long-term effects of poorly managed pain in babies, especially preterm babies," says Chambers. Research suggests unchecked childhood pain can delay healing, alter brain development, lead to chronic pain and increase the risk of opioid addiction later in life.

Pediatric pain has historically been managed poorly compared to adult pain, says Chambers. Although we have moved on from the dark days of not even anesthetizing babies undergoing surgery, children's pain is still undertreated. A 2011 paper in CMAJ, for instance, found that two-thirds of children in Canadian hospi- tals underwent painful procedures without appropriate pain management.

Part of the challenge of pain management in children is communication. Many patients are pre-verbal so their
Breastfeeding is a good example. "Breastfeeding during painful procedures is not just comforting; science has shown that it's a proven pain reliever," says Chambers. But sometimes health profes-

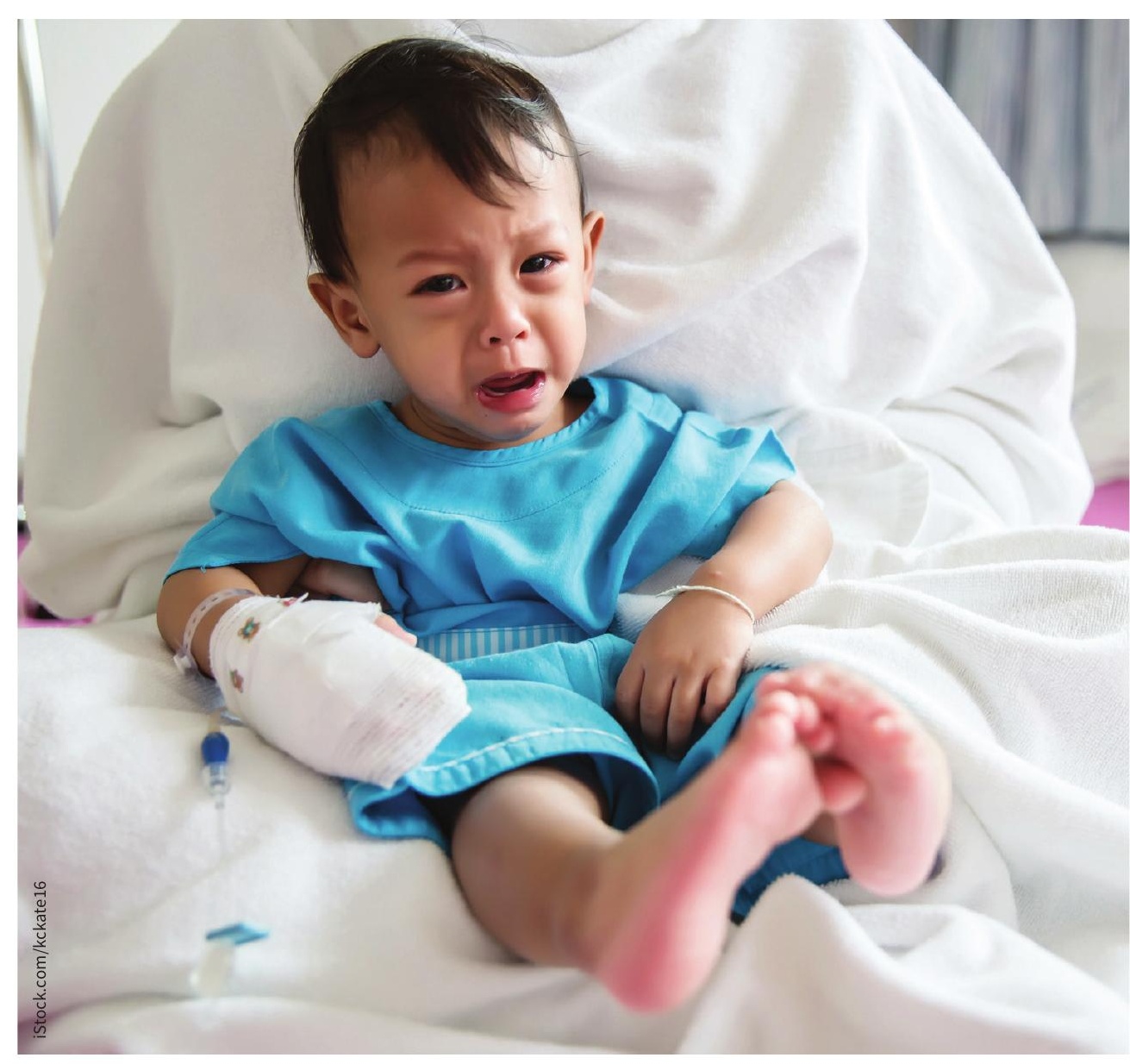

A campaign to manage pain better in children was recently launched in Canada.

need for pain relief is difficult to assess. But another part is not translating scientific findings into practice, says Chambers. "We have solutions that we know work to reduce pain, but often they just aren't used." sionals discourage it, expressing concern that babies will start associating eating with pain.

"There's not as much emphasis on pain management in kids," agrees Dr. Deepa Kattail, a pediatric anesthesiologist and 
pain researcher at McMaster University. "I think, overall, people are nervous." Even in children's hospitals, Kattail says, when kids are sent for blood work, phlebotomists will often not use anesthetic cream for fear it will be absorbed at toxic levels, and saying it's outside their scope of practice.

Breastfeeding, anesthetic cream, sucrose, distraction techniques, relaxation strategies, seating positions - all have been shown to mitigate pain, says Chambers, but they are not always employed when they should be.

"It speaks to the challenges of getting science out of the medical journals, out of the medical conferences, and into the hands of people who can actually implement it," says Chambers, pointing out that it can take as long as 17 years to get research to the front lines or practice. "In pediatrics, 17 years is too long. It's a whole generation of kids who miss out on knowledge."

According to Doug Maynard, associate director of business development at Children's Healthcare Canada, a nonprofit that has teamed with SKIP, hospitals must be more engaged at the systems level. Good pediatric pain control has to become part of the accreditation process, he says. "You have to have hospital administrators' buy-in."

Dr. Fiona Campbell, director of the chronic pain clinic at The Hospital for Sick Children, agrees that accreditations, such as ChildKind International, can help put pressure on institutions to do the right thing. But she thinks more is needed to change how Canada addresses pain management in general.

In April, the federal government launched the Canadian Pain Task Force to investigate how the country is doing on managing pain and if it can do better. Campbell, who is president of the Canadian Pain Society, is cochair of the task force. She points out that the Canadian economy loses $\$ 60$ billion every year to the direct and indirect costs of pain. We also lose lives; people in chronic pain have double the risk of dying by suicide. "We've been pushing for a long time to get a national pain strategy," says Campbell.

Alison Motluk, Toronto, Ont. 